\title{
'|||||||||||||||||||||||||||||||||||||||||||||||||||||||||||||||||||.
}

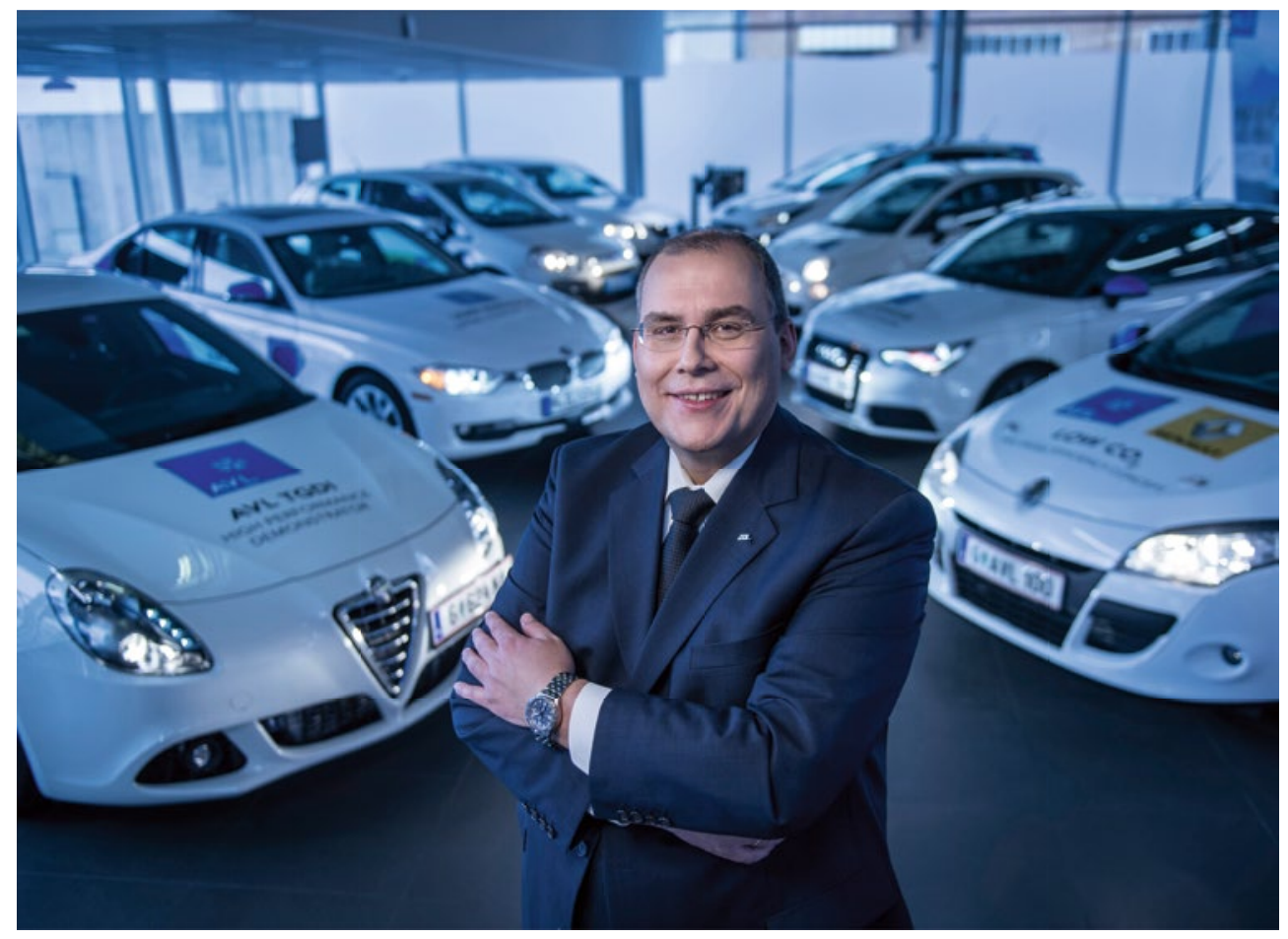

Prof. Dr.-Ing. Uwe Dieter Grebe Geschäftsführer, AVL List GmbH

\section{Ausgewogene Fahrzeugeigenschaften}

Eine der größten Herausforderungen der Automobilbranche stellt die weitere Reduktion der $\mathrm{CO}_{2}$-Emissionen dar, während gleichzeitig die kundenrelevanten Fahrattribute Dynamik und Komfort verbessert werden müssen. Hierzu sind vernetzte Entwicklungsabläufe mit simultaner Optimierung der teilweise konkurrierenden Anforderungen für den Antriebsstrang und das Fahrzeug notwendig.

Für die kosteneffiziente $\mathrm{CO}_{2}$-Reduzierung müssen die Energieketten des gesamten Fahrzeugs betrachtet werden. Es gilt, die richtige Balance zwischen Kraftstoffverbrauch, Produktkosten und kundenrelevanten Fahreigenschaften zu finden. Neue Ansätze lassen sich erst ableiten, wenn die Wirkzusammenhänge aller Energieflüsse - mechanisch, thermisch, elektrisch, hydraulisch und pneumatisch - verstanden sind und simultan mit den fahrrelevanten Eigenschaften bewertet werden.

Die AVL nutzt dafür ihre Kernkompetenz im Bereich der Antriebstechnik und erweitert diese durch einen energetischen Blickwinkel auf das gesamte Fahrzeug. Die Vergangenheit hat mehrfach gezeigt, dass die $\mathrm{CO}_{2}$-Reduzierung allein für einen Markterfolg nicht ausreicht. Die Kunden suchen ein ausgewogenes Fahrzeug und kein Produkt mit Verzichtserklärung. Die AVL hat deshalb das bewährte Entwicklungswerkzeug AVL-Drive deutlich ausgebaut und kann damit die vom Kunden wahrgenommenen Fahreigenschaften vollständig bewerten. Mit der Version 4.0 des Werkzeugs können erstmals gesamtheitlich alle kundenrelevanten Fahrattribute objektiv bewertet werden, wie zum Beispiel Performance, Fahrdynamik, Fahrbarkeit, ADAS-Funktionen, Handling, Federungskomfort und Verbrauch, aber auch Energieeffizienz, Geräusch und Sound.

Das Verfahren kann im Fahrzeug, auf leistungsfähigen Prüfständen und in der Computersimulationsumgebung eingesetzt werden. So lassen sich bereits in einer frühen Entwicklungsphase Auswirkungen von $\mathrm{CO}_{2}$-Maßnahmen auf das Beschleunigungsvermögen, die Fahrdynamik, das Kurvenverhalten und den Fahrkomfort beurteilen. Fahrzeugeigenschaften können bereits in der Konzeptphase ausbalanciert werden, damit der Charakter des Fahrzeugs erhalten bleibt. Mit der zusätzlichen Berücksichtigung der Kosten lässt sich so ein energetisch optimiertes Fahrzeug entwickeln, das bezahlbar bleibt und die Kundenerwartungen erfüllt.

Um Synergien zu erschließen, müssen auch die Entwicklungsabläufe neu geordnet werden. Beispielsweise sind die Beiträge der Aerodynamikingenieure mit der Verbesserung der Formgebung des Fahrzeugs begrenzt. Entwicklungssprünge kann es aber geben, wenn die Durchströmung konsequent bedarfsorientiert konzipiert und gemeinsam mit einem intelligenten Fahrzeug-Thermomanagement ausgelegt wird. In der Zukunft ist eine stärkere bereichsübergreifende Zusammenarbeit in der Fahrzeugentwicklung notwendig. 